\title{
Desempenho acadêmico e frequência dos estudantes ingressantes pelo Programa de Inclusão da UNESP
}

\author{
Academic performance and attendance at classes of \\ students who entered through Inclusion Program of UNESP
}

Eduardo Galhardo ${ }^{1}$ - ${ }^{1}$ Universidade Estadual Paulista | Faculdade de Ciências e Letras | Assis | SP | Brasil. Contato: eduardo.galhardo@unesp.br. ORCID: https://orcid.org/0000-00019953-1458

Mário Sérgio Vasconcelos ${ }^{2}$ - ${ }^{2}$ Universidade Estadual Paulista | Faculdade de Ciências e Letras | Assis | SP | Brasil. Contato: mario.sergio@unesp.br. ORCID: https://orcid.org/0000-0002$\underline{3977-827 X}$

Fernando Frei ${ }^{3}-{ }^{3}$ Universidade Estadual Paulista | Faculdade de Ciências e Letras | Assis | SP | Brasil. Contato: fernando.frei @unesp.br. ORCID: https://orcid.org/0000-0002-3354-8430

Edgar Bendahan Rodrigues ${ }^{4}$ - ${ }^{4}$ Universidade Estadual Paulista $\mid$ Faculdade de Ciências e Letras | Assis | SP | Brasil. Contato: edgarbendahan@ hotmail.com. https://orcid.org/0000$\underline{0002-3406-6257}$

Resumo: Este artigo tem por objetivo realizar uma análise preliminar sobre o Projeto de Inclusão desenvolvido na Universidade Estadual Paulista (UNESP) por meio do Sistema de Reserva de Vagas da Educação Básica Pública (SRVEBP). Mais especificamente, buscou-se realizar um estudo sobre o desempenho acadêmico e a frequência às aulas em grupos compostos por estudantes que ingressaram pelo sistema universal, egressos de escola pública e autodeclarados pretos, pardos ou indígenas, matriculados na UNESP em 2014, 2015, 2016 e 2017. Além disso, foram realizadas essas mesmas análises em cursos de graduação de alta demanda social e em cursos de baixa demanda social. Os dados foram coletados no Sistema de Graduação da UNESP (SISGRAD) e o desempenho acadêmico analisado por meio do coeficiente de rendimento, média ponderada e índice de desempenho. De um modo geral os resultados indicam que não há diferenças relevantes entre o desempenho acadêmico dos estudantes que ingressaram pelo Sistema Universal e os que ingressaram pelo SRVEBP. Entretanto, observou-se um maior coeficiente de variação nos grupos analisados em cursos de baixa demanda social.

Palavras-chave: Desempenho acadêmico. Inclusão na universidade. UNESP.

Abstract: This article has the aim to make a preliminary analyze about the Inclusion Program developed by São Paulo State University (UNESP) through Vacancies Booking Public Basic Education (SRVEBP). More specifically, we looked for making a study about the academic performance and attendance at classes inside groups formed by students who entered through the Universal System, who left public schools and are self-declared black, brown or indigenous, enrolled at UNESP in 2014, 2015, 2016 and 2017. Beyond this, were realized these same analyses at graduation courses of high social demand and courses of low social demand. The data were collected from Graduation System of UNESP (SISGRAD) and the academic performances analyzed through the yield coefficient, weighted media and performance index. In general, the results show that there are not relevant difference between the academic performance of students who entered through Universal System and those who entered through SRVEBP. However, a higher coefficient of variation was observed in the groups analyzed in courses with low social demand.

Keywords: Academic success. Inclusion at university. UNESP.

- Recebido em: 9 de outubro de 2019 • Aprovado em: 6 de agosto de 2020

DOI: http://dx.doi.org/10.1590/S1414-40772020000300010

Este é um artigo publicado em acesso aberto sob uma licença Creative Commons

https://creativecommons.org/licenses/by-nc/4.0/ 


\title{
Introdução
}

Um marco para a adoção de políticas de ações afirmativas para o ingresso nas universidades brasileiras no início deste século foi o pioneirismo da Universidade do Estado do Rio de Janeiro (UERJ) que, no vestibular de 2003, reservou vagas para selecionar candidatos de escolas públicas. Logo em seguida, em 2004, destaca-se a Universidade de Brasília (UnB), que foi a primeira universidade federal do Brasil a adotar uma política de cotas raciais, reservando $20 \%$ das vagas do vestibular para aqueles que se declarassem e fossem considerados negros por uma banca avaliadora. Posteriormente, outras Universidades implementaram ações afirmativas de formas diversas e, em 2012, já constavam 162 instituições públicas de ensino superior que haviam implantado programas dessa natureza (CARVALHO, 2016).

Dois importantes fatos que contribuíram para a continuidade dessas ações ocorreram em 2012. O primeiro foi a decisão unânime do Supremo Tribunal Federal (STF) sobre a constitucionalidade das cotas raciais e sociais; o segundo foi a publicação da Lei $\mathrm{n}^{\mathrm{o}} 12.711 / 2012$, que dispõe sobre as formas de ingresso nas universidades federais e institutos federais de educação. Esta lei estabelece os percentuais de vagas destinadas às cotas sociais e raciais, com o intuito de democratizar o acesso ao ensino superior no Brasil (BRASIL, 2012). Tais fatos foram determinantes para que instituições estaduais e municipais de ensino superior também passassem a adotar políticas de ações afirmativas (VELLOSO, 2009; GARCIA; JESUS, 2015; VASCONCELOS; GALHARDO, 2016; GUERRINI et al., 2018).

Lima, Neves e Silva (2014) analisaram, na perspectiva histórica, a adoção das políticas de ações afirmativas na universidade e ressaltaram que a ideia de ação afirmativa associada ao sistema de reserva de vagas, popularmente conhecido como cotas, se tornou a principal fonte de política social nas universidades brasileiras. Os autores asseveram, ainda, que:

\begin{abstract}
As análises nos conduzem a pensar que, independentemente de resolverem ou não a flagrante desigualdade entre brancos e negros no nosso país, as políticas de ação afirmativa, com destaque para as cotas raciais, estimulam o debate sobre raça, racialização, justiça e racismo numa sociedade que sempre pareceu dormir no berço esplêndido do mito da democracia racial. Se as cotas são "certas" ou "erradas", "justas" ou "injustas", é um tema de profundos debates e polêmicas. Para nós, no entanto, não restam dúvidas de que elas têm permitido um enorme avanço no interesse e produção de reflexões sobre o racismo no Brasil (LIMA; NEVES; SILVA, 2014, p. 158).
\end{abstract}

Nos últimos anos houve um aumento significativo de publicações sobre a efetividade das políticas de ações afirmativas nas universidades (VIDIGAL, 2018). Wainer e Melguizo (2018), por exemplo, fazem uma importante revisão bibliográfica apontando para os principais resultados de trabalhos que comparam o desempenho de cotistas e não cotistas e destacam, entre 
outras conclusões, que "não há diferença prática entre o conhecimento de alunos cotistas e o de seus colegas de classes não cotistas ao final do curso, se assumimos que o exame do Enade mede tanto habilidades gerais de raciocínio como conhecimentos específicos do curso" (WAINER; MELGUIZO, 2018, p. 13).

Várias outras pesquisas realizadas nas universidades que adotaram o sistema de cotas para estudantes de escolas públicas (EPs) trazem dados expressivos ao tratarem de discussões que incluem a justiça social, o preconceito, a reparação de direitos, o desempenho, a permanência, a retenção e a evasão dos ingressantes (WAINER; MELGUIZO, 2018; MENDES JUNIOR, 2014; MENIN et al., 2008). Porém, as vertentes mais pesquisadas partem da comparação dos coeficientes de rendimento (CR) e taxas de graduação e evasão de grupos focais compostos de estudantes não cotistas e cotistas. A esse respeito, Mendes Junior (2014) destaca que os cotistas tendem a atribuir um alto valor aos cursos nos quais ingressaram, por isso persistem em maior proporção na universidade. Outro fator frequentemente estudado é o perfil socioeconômico do estudante ingressante comparado ao desempenho nas disciplinas da graduação, no vestibular e até mesmo na escolha de carreiras de maior ou menor prestígio social. Resultados apontam a influência marcante desta variável (SOUZA, 2012; ZAGO, 2006).

De modo geral, constata-se que a maioria das pesquisas aponta para aspectos positivos e negativos relacionados à política de cotas, porém quase sempre os pontos positivos dão suportes para justificativas contundentes a favor da introdução de ações afirmativas que possibilitem a superação dos possíveis obstáculos para inserção ao ensino superior (MENDES JUNIOR, 2014; VIBETTO, 2014; CERVI, 2013; WINTHER; GOLGHER, 2010; VELLOSO, 2009; CARDOSO, 2008).

Em se tratando de políticas afirmativas no ensino superior do estado de São Paulo, em 2012, o governo estadual solicitou por meio do Programa Paulista de Inclusão Social no Ensino Superior (PPISES), que a USP, UNESP e UNICAMP implantassem políticas de ações afirmativas de maior abrangência para estudantes de escolas públicas, pretos, pardos e indígenas. Foi neste contexto que o Conselho Universitário da Universidade Estadual Paulista 'Júlio de Mesquita Filho' (UNESP) aprovou, em agosto de 2013, proposta para atender às metas de inclusão em todos os seus cursos e turmas de graduação. ${ }^{1}$

\footnotetext{
${ }^{1} \mathrm{Na}$ época, em razão de suas especificidades e discussões internas, UNESP, UNICAMP e USP implantaram diferentes programas de inclusão.
} 


\section{O programa de inclusão na UNESP}

A UNESP, desde 2010, vem ampliando seus programas de ações afirmativas (cursinhos pré-vestibulares, isenções de taxas no vestibular, bolsas, auxílios permanência, restaurantes universitários, moradias estudantis, entre outros). Mas foi a partir de 2014 que implantou o Sistema de Reserva de Vagas para a Educação Básica Pública (SRVEBP). Assim, para atender às metas inclusivas de alunos oriundos de escolas públicas (EP) e de estudantes autodeclarados pretos, pardos e indígenas (PPI) em seus cursos de graduação, o projeto de inclusão da UNESP previu o seguinte: a) 50\% das vagas, para cada curso e turno, dos cursos de graduação da UNESP devem ser preenchidas por estudantes que cursaram integralmente o ensino médio em escolas públicas; b) do total de vagas a serem ocupadas por estudantes oriundos de escolas públicas, 35\% serão reservadas para pretos, pardos e indígenas; c) no prazo de 5 (cinco) anos, a universidade deverá atingir a meta de inclusão de estudantes de escola pública em $50 \%$ das vagas, sendo $15 \%$ em 2014, 25\% em 2015, 35\% em 2016, 45\% em 2017 e $50 \%$ em 2018; d) a metodologia adotada para a inclusão no referido SRVEBP, com base na classificação no concurso vestibular, com a convocação dos candidatos aprovados até o limite de vagas fixadas para cada curso e turno.

A Tabela 1 apresenta a evolução da distribuição de estudantes da UNESP de acordo com o sistema de ingresso, ou seja, pelo Sistema Universal e pelo SRVEBP + Pretos, Pardos e Indígenas (PPI).

Tabela 1 - Distribuição do número de estudantes por sistema de ingresso nos vestibulares da UNESP, no período de 2014 a 2018

\begin{tabular}{lcccccc}
\hline \multicolumn{1}{|c}{ Sistema de Ingresso } & $\mathbf{2 0 1 4}$ & $\mathbf{2 0 1 5}$ & $\mathbf{2 0 1 6}$ & $\mathbf{2 0 1 7}$ & $\mathbf{2 0 1 8}$ & Total \\
\hline Vagas & 7.679 & 7.691 & 7.715 & 7.725 & 7.725 & 38.535 \\
Sistema Universal & 6.482 & 5.740 & 4.986 & 4.222 & 3.847 & 25.277 \\
SRVEBP & 785 & 1.356 & 1.774 & 2.297 & 2.515 & 8.727 \\
PPI & 412 & 595 & 955 & 1.206 & 1.363 & 4.531 \\
& & & & & & \\
SRVEBP + PPI & 1.197 & 1.951 & 2.729 & 3.503 & 3.878 & 13.258 \\
& $(15 \%)$ & $(25 \%)$ & $(35 \%)$ & $(45 \%)$ & $(50 \%)$ & \\
\hline
\end{tabular}

Fonte: PROGRAD/VUNESP/COPE.

No período de 2014 a 2018, a UNESP ofereceu 38.535 vagas. Destas, 13.258 pelo Sistema de Reserva de Vagas para Educação Básica Pública (SRVEBP). Das vagas destinadas ao SRVEBP, 4.531 vagas (35\%) foram destinadas aos candidatos que se autodeclararam pretos, 
pardos ou indígenas. ${ }^{2}$ Os dados revelam que este programa de inclusão está atingindo as metas estabelecidas. Em 2017 e em 2018, respectivamente 50,1\% e 54,4\% dos ingressantes já eram de escolas públicas (Gráfico 1). Além disso, pode-se observar que, após a implantação do programa de inclusão na UNESP, o percentual de alunos pretos, pardos ou indígenas assumiu uma tendência ascendente. Em 2017, 18\% dos alunos ingressantes matriculados na UNESP foram PPIs e, em 2018, foram matriculados $20 \%$ de autodeclarados PPI.

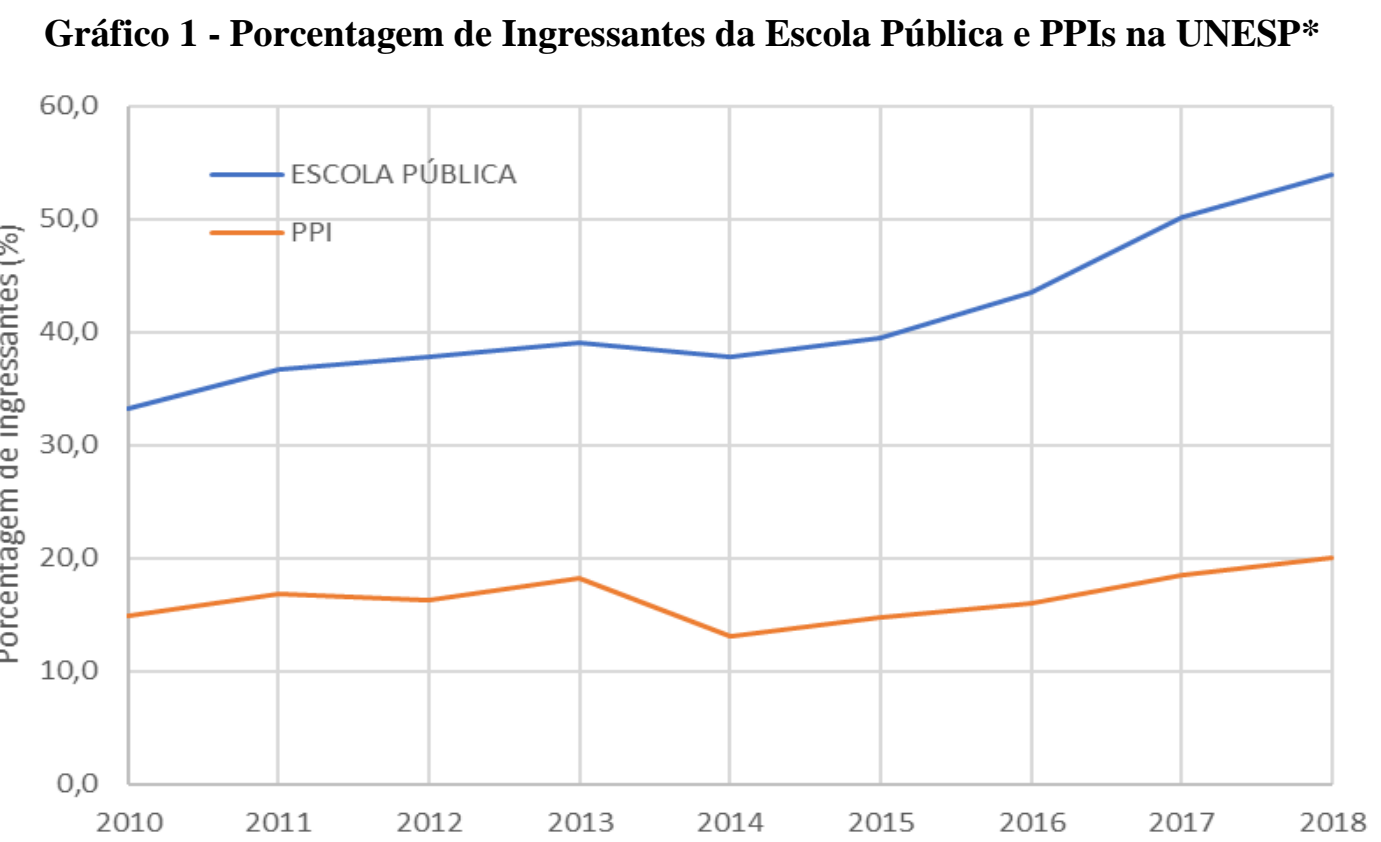

Fonte: COPE/PROGRAD/VUNESP.

* Os dados anteriores a 2014 não podem ser considerados consolidados, pois o registro preciso de autodeclaração como PPI se iniciou apenas no ano de 2014, em decorrência do Projeto de Inclusão da UNESP.

O programa de inclusão implantado na UNESP está, cada vez mais, alterando o perfil socioeconômico dos estudantes. Embora o SRVEBP tenha sido implantado a partir de 2014, desde 2010 (ano em que a UNESP começou a ampliar seus programas de ações afirmativas) até 2018, vem aumentando o número de estudantes ingressantes provenientes de famílias com renda per capita de 1,5 salário mínimo (de 2.053 para 3.155 estudantes). O mesmo ocorre com alunos oriundos de famílias com renda de 1,6 a 2,0 salários mínimos (de 1.029 para 1.461). No entanto, observa-se uma tendência inversa na quantidade de alunos ingressantes com renda per capita familiar acima de 2,0 salários mínimos (diminuiu de 3.285 para 2.646). O Gráfico 2

\footnotetext{
$2 \mathrm{Na}$ inexistência de candidatos autodeclarados pretos, pardos ou indígenas classificados, as vagas foram preenchidas por candidatos que tenham cursado o Ensino Médio integralmente em Escolas Públicas.
} 
retrata a tendência observada na UNESP, sobretudo nos anos de 2017 e 2018, anos nos quais a inclusão foi de, respectivamente, $45 \%$ e $50 \%$ de alunos de egressos de escolas públicas.

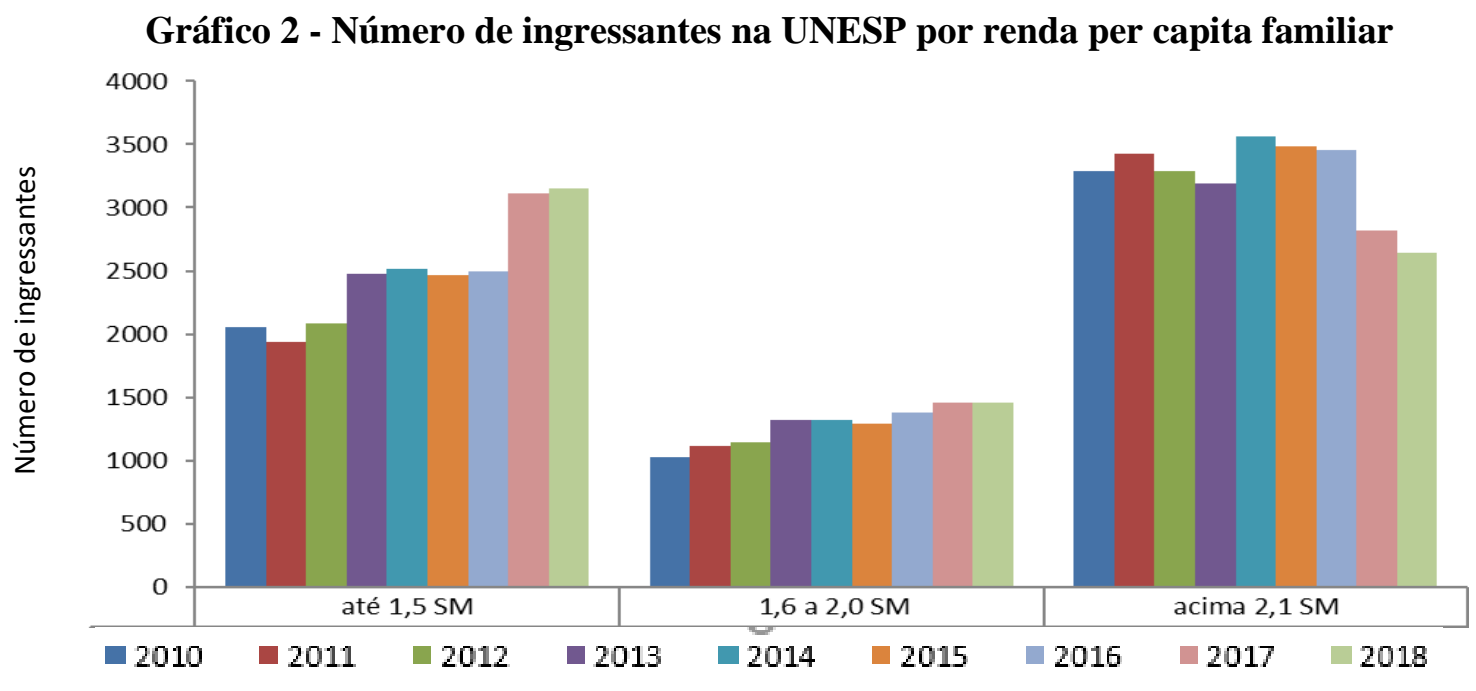

Fonte: VUNESP.

Sem dúvida, a inclusão definiu um novo perfil no quadro de estudantes da UNESP e, em consequência, aumentou anualmente a quantidade de estudantes que solicitam auxílios de permanência estudantil, especialmente os estudantes que ingressaram pelo SRVEBP.

Ciente de que o programa de inclusão alteraria o perfil socioeconômico dos estudantes e que haveria aumento de demandas para a permanência desses estudantes na universidade, a UNESP, em 2013, na mesma sessão do Conselho Universitário que aprovou o Programa de Inclusão, criou a Coordenadoria de Permanência Estudantil (COPE). Esta Coordenadoria tem como objetivo de elaborar, desenvolver e avaliar ações para promover a igualdade de oportunidades aos estudantes que se encontram em situação de vulnerabilidade socioeconômica e contribuir para a redução de índices de retenção e de evasão na universidade. As principais metas da COPE ficaram assim definidas: planejar ações para receber alunos que ingressarem na UNESP pelo Programa de Inclusão por meio do SRVEBP; e, introduzir na Unesp as diretrizes do Programa Nacional de Assistência Estudantil - PNAES (BRASIL, 2010), que visa, em especial, atender estudantes oriundos da rede pública de educação básica com renda per capita de até 1,5 salário mínimo.

Em 2017, atenta aos estudos que ressaltam a importância de programas consistentes de assistência aos estudantes para que possa se evitar a evasão (NUNES; VELOSO, 2016; VASCONCELOS; GALHARDO, 2016), a COPE, também considerando a experiência decorrente do processo de implantação do projeto de inclusão e visando melhor atender as demandas dos estudantes em situação de vulnerabilidade socioeconômica, reformulou as 
modalidades de assistência aos estudantes e passou a oferecer os seguintes auxílios de permanência: Moradia Estudantil (ME), Auxílio Socioeconômico (ASE), Auxílio Aluguel (AA), Subsídio Alimentação (SA), Auxílio Especial (AE) e Auxílio Estágio (AEs). No período de 2014 a 2018, todos os estudantes que solicitaram auxílios de permanência e que atenderam aos critérios definidos pela UNESP foram atendidos. Foram contemplados 17.638 estudantes.

Desde 2014, observa-se uma tendência crescente na quantidade de estudantes que solicitam auxílios de permanência e que ingressaram na Unesp por meio do Programa de Inclusão. Em 2014, 2.877 destes estudantes solicitaram auxílios. Em 2018, praticamente dobrou a quantidade, foram 5.659 solicitações. Em 2017, por exemplo, 61\% dos auxílios atribuídos pela permanência estudantil foram para estudantes que ingressaram por meio do Projeto de Inclusão. Em 2018, esse contingente de auxílios atingiu 70\%. As projeções indicam que esta tendência continuará crescente nos próximos anos e que ações de assistência aos alunos deverão ser reforçadas para que, conforme destaca Correio (2018), se consolide a permanência evitando a evasão de estudantes da universidade.

\section{A pesquisa}

Considerando o novo contexto inclusivo que se configurou no ensino superior brasileiro e no estado de São Paulo, torna-se cada vez mais importante a realização de estudos sobre os estudantes que vivenciam tal situação, sobretudo para que os projetos de inclusão possam ser avaliados e aprimorados. Visando contribuir para uma análise mais aprofundada desta realidade, encontra-se em andamento na UNESP alguns projetos de pesquisa com o propósito de compreender os impactos e as consequências da implantação do Sistema de Reserva de Vagas para Educação Básica Pública (SRVEBP). ${ }^{3}$ Entre esses projetos elaborou-se o estudo denominado "Análise do desempenho acadêmico dos estudantes ingressantes pelo programa de Inclusão da UNESP”. No presente artigo é realizada uma análise preliminar dos dados deste estudo que tem por objetivos:

a) Comparar os valores médios de desempenho acadêmico (coeficiente de rendimento, média ponderada e índice de desempenho) e frequência dos estudantes matriculados em 2014, 2015, 2016 e 2017, que ingressaram na universidade por opção de vestibular nos grupos: (1) sistema universal, (2) egressos de escola pública e (3) autodeclarados Pretos, Pardos e Indígenas.

\footnotetext{
3 A Pró-reitoria de Graduação (PROGRAD) está coordenando o projeto "Política de reserva de vagas na UNESP: análise da evasão a partir das categorias de ingressantes".
} 
b) Comparar os valores médios de desempenho acadêmico (coeficiente de rendimento, média ponderada e índice de desempenho) e frequência dos estudantes matriculados em 2014, 2015, 2016 e 2017, que ingressaram na universidade por opção de vestibular nos grupos: (1) sistema universal, (2) egressos de escola pública e (3) autodeclarados Pretos, Pardos e Indígenas, em cursos de alta demanda social (mais de 25 candidatos/vaga).

c) Comparar os valores médios de desempenho acadêmico (coeficiente de rendimento, média ponderada e índice de desempenho) e frequência dos estudantes matriculados em 2014, 2015, 2016 e 2017, que ingressaram na universidade por opção de vestibular nos grupos: (1) sistema universal, (2) egressos de escola pública e (3) autodeclarados Pretos, Pardos e Indígenas, em cursos de baixa demanda social (menos de 3 candidatos/vaga).

\section{Método}

Um aspecto metodológico que merece destaque neste estudo é o fato de não se utilizar uma amostra, uma vez que estão sendo analisados os dados referentes à população total de estudantes ingressantes na UNESP em cada um dos anos entre 2014 e 2017. Os dados constam no Sistema de Graduação da UNESP (SISGRAD) e foram extraídos de um banco de dados que contém dados sobre cada estudante que ingressou no referido período. ${ }^{4}$ No total, o banco de dados apresenta 35.294 linhas (estudantes), distribuídos em 52 variáveis. Para a pesquisa em pauta foram analisadas as seguintes variáveis: Coeficiente de Rendimento (média das notas finais das disciplinas cursadas - mínima zero e máxima dez); Média Ponderada (média das notas finais das disciplinas cursadas considerando a carga horária da disciplina); Índice de Desempenho (\% de disciplinas em que foi aprovado entre as que estava matriculado); Frequência Média (\% de comparecimento às atividades das disciplinas no referido ano); Coeficiente de Rendimento em cada ano cursado; e, Média Ponderada em cada ano cursado.

Do total de estudantes matriculados, no período de 2014 a 2017, para a realização das comparações não foram incluídos somente os estudantes do Núcleo de Educação a Distância (curso não presencial de ingresso diferenciado no qual não há programa de inclusão) e os que tiveram sua chamada do vestibular cancelada por não comparecimento e que, consequentemente, foram substituídos por outros estudantes da lista de espera do vestibular, ou seja, dos 35.294 estudantes listados, foram analisados, neste estudo inicial, os dados de 30.838 estudantes.

4 Quando se iniciou este estudo, ainda não estavam disponíveis no SISGRAD todos os dados de 2018 consolidados. Numa próxima etapa da pesquisa serão incluídos os dados de 2018 e 2019. 
Os tamanhos populacionais para grupos de estudantes por ano e forma de ingresso podem ser observados na Tabela 2. No período de 2014 a 2017 ingressaram 18.098 estudantes pelo Sistema Universal, 8.109 pelo SRVEBP (EP) e 4.631 pelo SRVEBP que se autodeclararam pretos, pardos ou indígenas (PPI). ${ }^{5}$

Tabela 2 - Tamanho populacional dos grupos de estudantes, por ano e forma de ingresso ${ }^{6}$

\begin{tabular}{ccccc}
\hline & Sistema Universal & Escola Pública & PPI & TOTAL \\
\hline $\mathbf{2 0 1 4}$ & 5062 & 1704 & 881 & 7647 \\
$\mathbf{2 0 1 5}$ & 4705 & 1842 & 1096 & 7643 \\
$\mathbf{2 0 1 6}$ & 4414 & 2112 & 1225 & 7751 \\
$\mathbf{2 0 1 7}$ & 3917 & 2451 & 1429 & 7797 \\
Total & 18098 & 8109 & 4631 & 30838 \\
\hline
\end{tabular}

Fonte: COPE/SISGRAD/PROGRAD.

A análise dos dados desta pesquisa não foi realizada por meio de inferência estatística, pois a inferência compreende a aplicação de métodos fundamentados em probabilidade para analisar dados amostrais a fim de se conhecer características de uma população inacessível em sua totalidade. Não foi utilizado tal processo, pois dispõe-se de toda a população para análise, utilizando medidas gráficas e sintéticas que representam esta população.

\section{Resultados e discussão}

Na Tabela 3 são apresentados os resultados da análise dos grupos de estudantes cotistas e não cotistas, por ano e por forma de ingresso, e as respectivas médias referentes ao desempenho acadêmico.

5 EP e PPI são cotistas.

${ }^{6}$ Desde 2018, 50\% dos estudantes ingressantes na UNESP são de escolas públicas e, destes, 35\% das vagas reservadas para PPIs. Seguindo o mesmo procedimento nos anos subsequentes, em 2022, no mínimo $50 \%$ de todos os alunos da UNESP, por curso e turno, serão de escolas públicas. 
Tabela 3 - Médias do desempenho acadêmico de cotistas e não cotistas dos estudantes da UNESP, por ano, no período de 2014 a 2017

\begin{tabular}{|c|c|c|c|c|c|c|c|c|c|}
\hline \multirow[t]{2}{*}{2014} & \multicolumn{3}{|c|}{$\begin{array}{c}\text { Coeficiente } \\
\text { Rendimento }\end{array}$} & \multicolumn{3}{|c|}{$\begin{array}{c}\text { Média } \\
\text { Ponderada }\end{array}$} & \multicolumn{3}{|c|}{$\begin{array}{c}\text { Índice } \\
\text { Desempenho }\end{array}$} \\
\hline & SU & EP & PPI & SU & EP & PPI & SU & EP & PPI \\
\hline Média & 6,14 & 6,01 & 5,57 & 6,07 & 5,95 & 5,51 & 82,88 & 80,64 & 76,49 \\
\hline Mediana & 6,67 & 6,73 & 6,23 & 6,57 & 6,67 & 6,14 & 96,12 & 95,18 & 93,05 \\
\hline $\begin{array}{l}\text { Desvio } \\
\text { Padrão }\end{array}$ & 2,27 & 2,52 & 2,66 & 2,28 & 2,55 & 2,69 & 25,07 & 27,25 & 29,74 \\
\hline CV $(\%)$ & 36,97 & 41,93 & 47,76 & 37,56 & 42,86 & 48,82 & 30,25 & 33,79 & 38,88 \\
\hline \multirow[t]{2}{*}{2015} & \multicolumn{3}{|c|}{$\begin{array}{c}\text { Coeficiente } \\
\text { Rendimento }\end{array}$} & \multicolumn{3}{|c|}{$\begin{array}{c}\text { Média } \\
\text { Ponderada }\end{array}$} & \multicolumn{3}{|c|}{$\begin{array}{c}\text { Índice } \\
\text { Desempenho }\end{array}$} \\
\hline & SU & EP & PPI & SU & EP & PPI & SU & EP & PPI \\
\hline Média & 6,29 & 6,26 & 6,05 & 6,22 & 6,20 & 5,92 & 84,36 & 82,41 & 81,98 \\
\hline Mediana & 6,74 & 6,89 & 6,57 & 6,65 & 6,80 & 6,45 & 96,77 & 96,67 & 94,81 \\
\hline $\begin{array}{l}\text { Desvio } \\
\text { padrão }\end{array}$ & 2,15 & 2,33 & 2,39 & 2,17 & 2,36 & 2,41 & 23,37 & 26,25 & 25,04 \\
\hline $\mathrm{CV}(\%)$ & 34,18 & 37,22 & 39,50 & 34,89 & 38,06 & 40,71 & 27,70 & 31,85 & 30,54 \\
\hline \multirow[t]{2}{*}{2016} & \multicolumn{3}{|c|}{$\begin{array}{c}\text { Coeficiente } \\
\text { Rendimento }\end{array}$} & \multicolumn{3}{|c|}{$\begin{array}{c}\text { Média } \\
\text { Ponderada } \\
\end{array}$} & \multicolumn{3}{|c|}{$\begin{array}{c}\text { Índice } \\
\text { Desempenho }\end{array}$} \\
\hline & SU & EP & PPI & SU & EP & PPI & SU & EP & PPI \\
\hline Média & 6,35 & 6,13 & 5,88 & 6,28 & 6,05 & 5,81 & 85,52 & 82,65 & 79,59 \\
\hline Mediana & 6,84 & 6,70 & 6,45 & 6,74 & 6,60 & 6,32 & 100,0 & 95,83 & 93,87 \\
\hline $\begin{array}{c}\text { Desvio } \\
\text { Padrão }\end{array}$ & 2,18 & 2,35 & 2,41 & 2,20 & 2,36 & 2,43 & 23,12 & 25,26 & 27,27 \\
\hline $\mathrm{CV}(\%)$ & 34,33 & 38,34 & 40,99 & 35,03 & 39,01 & 41,82 & 27,03 & 30,56 & 34,26 \\
\hline \multirow[t]{2}{*}{2017} & \multicolumn{3}{|c|}{$\begin{array}{c}\text { Coeficiente } \\
\text { Rendimento }\end{array}$} & \multicolumn{3}{|c|}{$\begin{array}{c}\text { Média } \\
\text { Ponderada }\end{array}$} & \multicolumn{3}{|c|}{$\begin{array}{c}\text { Índice } \\
\text { Desempenho }\end{array}$} \\
\hline & SU & EP & PPI & SU & EP & PPI & SU & EP & PPI \\
\hline Média & 6,68 & 6,37 & 5,98 & 6,58 & 6,26 & 5,87 & 88,77 & 84,60 & 80,71 \\
\hline Mediana & 7,10 & 6,83 & 6,36 & 7,00 & 6,74 & 6,22 & 100,0 & 100,0 & 93,88 \\
\hline $\begin{array}{c}\text { Desvio } \\
\text { Padrão }\end{array}$ & 2,04 & 2,18 & 2,26 & 2,06 & 2,21 & 2,30 & 21,01 & 24,15 & 26,26 \\
\hline CV (\%) & 30,54 & 34,22 & 37,79 & 31,31 & 35,30 & 39,18 & 23,67 & 28,55 & 32,54 \\
\hline
\end{tabular}

Fonte: Os Autores.

Na Tabela 4 são apresentados os valores referentes à frequência de cotistas e não cotistas dos estudantes da UNESP, por ano, no período de 2014 a 2017. 
Tabela 4 - Médias das frequências de cotistas e não cotistas de toda a população de estudantes da UNESP, por ano, no período de 2014 a 2017

\begin{tabular}{cccc}
\hline $\mathbf{2 0 1 4}$ & \multicolumn{3}{c}{ Frequência Média } \\
\hline & SU & EP & PPI \\
Média & 84,90 & 83,46 & 81,29 \\
Mediana & 90,33 & 95,18 & 93,52 \\
Desvio Padrão & 15,25 & 17,05 & 18,22 \\
CV (\%) & 17,96 & 20,43 & 22,41 \\
\hline \multicolumn{4}{|c}{ Frequência Média } \\
\hline 2016 & EP & PPI \\
\hline \multicolumn{4}{c}{85,28} \\
Média & 87,24 & 86,46 & 90,83 \\
Mediana & 91,72 & 91,92 & 15,54 \\
Desvio Padrão & 13,82 & 15,07 & 18,22 \\
\hline CV (\%) & 15,84 & 17,43 & 1 \\
\hline
\end{tabular}

\begin{tabular}{|c|c|c|c|}
\hline \multirow[t]{2}{*}{2015} & \multicolumn{3}{|c|}{ Frequência Média } \\
\hline & SU & EP & PPI \\
\hline Média & 86,11 & 85,95 & 85,03 \\
\hline Mediana & 90,71 & 91,52 & 90,95 \\
\hline Desvio Padrão & 14,48 & 15,31 & 16,47 \\
\hline $\mathrm{CV}(\%)$ & 16,82 & 17,81 & 19,37 \\
\hline \multirow[t]{2}{*}{2017} & \multicolumn{3}{|c|}{ Frequência Média } \\
\hline & SU & EP & PPI \\
\hline Média & 89,16 & 88,64 & 87,51 \\
\hline Mediana & 93,08 & 92,97 & 91,97 \\
\hline Desvio Padrão & 13,03 & 13,66 & 14,24 \\
\hline CV (\%) & 14,61 & 15,41 & 16,27 \\
\hline
\end{tabular}

Fonte: Os Autores.

Considerando o coeficiente de rendimento (CR), a média ponderada, o índice de desempenho e a frequência média dos grupos analisados, os dados das Tabelas 3 e 4 revelam que as diferenças existentes entre os grupos formados pela forma de ingresso (SU, EP e PPI) são pouco relevantes quanto ao desempenho acadêmico geral. Contudo, o desvio padrão (DP) e o coeficiente de variação (CV), em alguns casos, são mais expressivos e se evidenciam no grupo PPI. Tais indicadores demandarão análises mais pormenorizadas e conjunturais para que se possa compreender melhor as dimensões do impacto da inclusão para estes grupos, principalmente porque tais dados não podem ser analisados de forma isolada. É preciso levar em conta a existência ou não de variáveis históricas direcionadas para esses grupos, bem como as ações institucionais de suportes materiais e acadêmicos vinculados ao programa de ação afirmativa que a universidade instituiu (CROSBY; IYER; SINCHAROEN, 2006). Para investigar de forma mais aprofundada a questão apontada, deve-se considerar outras variáveis como estruturas institucionais, perfil socioeconômico dos estudantes, situação familiar, desempenho no vestibular, faixa etária, assistência estudantil, etc. Essas variáveis ganham ainda maior relevância quando se analisa o desempenho acadêmico comparando cotistas e não cotistas em cursos de alta demanda e de baixa demanda no vestibular (VELLOSO, 2009; BIEMBENGUT; PACHECO; CONINCK, 2018).

Reiterando que este é um estudo preliminar, no qual estão sendo explorados os dados sem a realização de uma análise conjuntural mais aprofundada, analisa-se também, conforme anunciado em nossos objetivos, o rendimento acadêmico dos estudantes nos cursos da UNESP quanto à relação candidato/vagas, estabelecendo-se, assim, dois grupos de cursos que foram denominados: (1) cursos de alta demanda social e (2) cursos de baixa demanda social. Os 
cursos que apresentam uma alta relação de candidato/vaga como, por exemplo, o curso de medicina da UNESP, que é detentor da maior concorrência em vestibulares no Brasil (313 candidatos por vaga em 2018), está entre os 22 cursos com a relação superior a 25 candidatos/vaga que foram denominados de grupo de alta demanda social. Por outro lado, os 25 cursos com relação candidatos/vaga inferior a 3 constituem o grupo denominado de cursos com baixa demanda social. Tais cursos estão relacionados no Quadro 1, a seguir.

\section{Quadro 1 - Cursos de alta e baixa demanda social, com base na relação candidatos/vaga, relacionados em ordem alfabética}

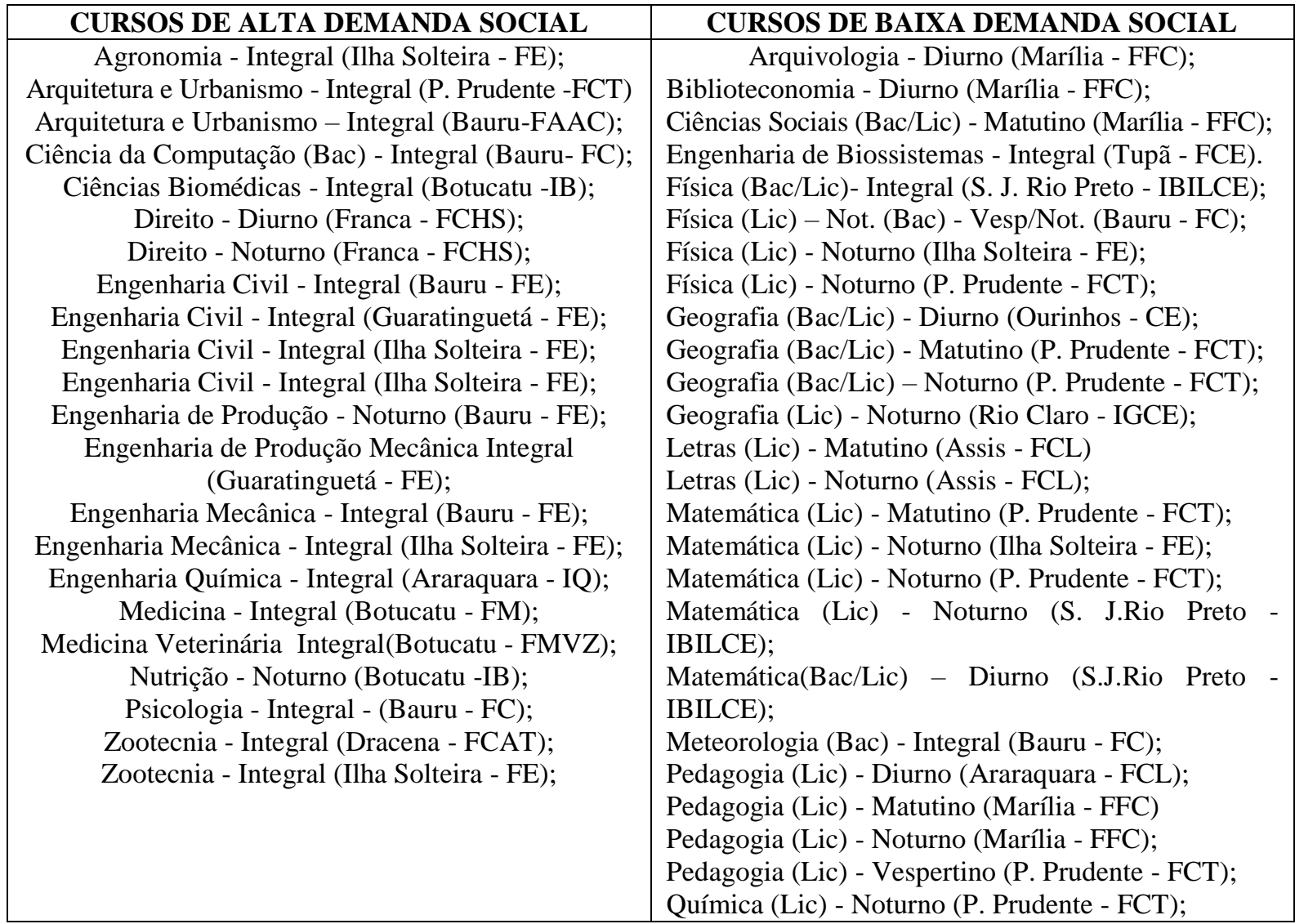

Fonte: Os Autores.

Nas Tabelas 5 e 6 são apresentadas as populações de estudantes para os anos pesquisados de acordo com os tipos de ingresso em cada uma das duas categoriais de alta e baixa demanda social. Na sequência (Tabelas 7 a 10), é feito um primeiro diagnóstico que decorre da comparação das medidas do coeficiente de rendimento (CR), índice de desempenho, média ponderada e frequência média dos estudantes para as duas categorias de demanda social em relação aos diferentes grupos formados pelo sistema de ingresso - SU, EP e PPI. A 
comparação realizada não se dá entre as categorias de alta e baixa demanda social, mas sim entre os grupos SU, EP e PPI dentro de cada categoria.

Tabela 5 - Tamanhos populacionais dos grupos de estudantes, por ano e forma de ingresso - alta demanda social

\begin{tabular}{ccccc}
\hline & Sistema Universal & Escola Pública & PPI & TOTAL \\
\hline $\mathbf{2 0 1 4}$ & 878 & 131 & 58 & 1067 \\
$\mathbf{2 0 1 5}$ & 767 & 172 & 97 & 1036 \\
$\mathbf{2 0 1 6}$ & 708 & 278 & 133 & 1119 \\
$\mathbf{2 0 1 7}$ & 588 & 353 & 171 & 1112 \\
\hline
\end{tabular}

Fonte: COPE/SISGRAD/PROGRAD.

Tabela 6 - Tamanhos populacionais dos grupos de estudantes, por ano e forma de ingresso baixa demanda social

\begin{tabular}{ccccc}
\hline & Sistema Universal & Escola Pública & PPI & TOTAL \\
\hline $\mathbf{2 0 1 4}$ & 455 & 374 & 257 & 1086 \\
$\mathbf{2 0 1 5}$ & 424 & 378 & 263 & 1065 \\
$\mathbf{2 0 1 6}$ & 454 & 374 & 266 & 1094 \\
$\mathbf{2 0 1 7}$ & 444 & 399 & 293 & 1136 \\
\hline
\end{tabular}

Fonte: COPE/SISGRAD/PROGRAD.

É possível se observar, na Tabela 5, que nos cursos de alta demanda social há uma diminuição na quantidade de ingressantes pelo sistema universal (diminuição de 29,4\%) e um aumento significativo de estudantes oriundos de escola pública (aumento de 19,4\%) e PPIs (aumento de 10\%). Por outro lado, nos cursos de baixa demanda social (Tabela 6), é praticamente estável a quantidade de alunos ingressantes pelo sistema universal (diminuição de $2,8 \%$ ), de escola pública (aumento de $0,7 \%$ ) e PPI (aumento de $2,1 \%$ ). Há um pequeno aumento de estudantes PPIs, mas bem menor se comparado aos cursos de alta demanda. Tais dados revelam que a inclusão nos cursos de baixa demanda não é expressiva, pois estes cursos historicamente já eram mais frequentados por alunos de escola pública e por PPIs.

A seguir, a Tabela 7 indica que não há diferenças relevantes entre as médias e medianas dos coeficientes de rendimento para os grupos SU, EP e PPI, tanto para a categoria de alta demanda social, quanto para a categoria de baixa demanda social. Porém, há um comportamento variável das médias e medianas dos grupos SU, EP e PPI nos cursos de baixa demanda. 
Tabela 7 - Resultados do Coeficiente de Rendimento para os grupos SU, EP e PPI em cursos de alta e baixa demanda social no período de 2014 a 2017

\begin{tabular}{|c|c|c|c|c|c|c|}
\hline 2014 & SU & EP & PPI & $\mathbf{S U}$ & EP & PPI \\
\hline & Alta & Alta & $\underline{\text { Alta }}$ & Baixa & Baixa & Baixa \\
\hline Média & 6,80 & 6,46 & 6,38 & 5,16 & 5,36 & 4,52 \\
\hline Mediana & 7,28 & 6,74 & 6,83 & 5,75 & 6,32 & 4,76 \\
\hline $\mathrm{DP}^{*}$ & 1,82 & 1,92 & 2,02 & 2,91 & 2,97 & 3,07 \\
\hline $\mathrm{CV}(\%)^{* *}$ & 26,76 & 29,72 & 31,66 & 56,40 & 55,41 & 67,92 \\
\hline \multirow[t]{2}{*}{2015} & SU & EP & PPI & SU & EP & PPI \\
\hline & Alta & Alta & Alta & Baixa & Baixa & Baixa \\
\hline Média & 6,88 & 6,93 & 6,38 & 5,23 & 5,39 & 5,65 \\
\hline Mediana & 7,19 & 7,19 & 6,57 & 5,67 & 6,14 & 6,33 \\
\hline $\mathrm{DP}^{*}$ & 1,77 & 1,61 & 1,87 & 2,80 & 2,86 & 2,71 \\
\hline $\mathrm{CV}(\%)^{* *}$ & 25,73 & 23,23 & 29,31 & 53,54 & 53,06 & 47,96 \\
\hline \multirow[t]{2}{*}{2016} & SU & EP & PPI & SU & EP & PPI \\
\hline & Alta & Alta & Alta & Baixa & Baixa & Baixa \\
\hline Média & 6,98 & 6,54 & 5,94 & 5,29 & 4,98 & 5,00 \\
\hline Mediana & 7,29 & 6,76 & 6,30 & 5,93 & 5,24 & 5,59 \\
\hline $\mathrm{DP}^{*}$ & 1,65 & 1,81 & 1,97 & 2,90 & 2,97 & 3,09 \\
\hline $\mathrm{CV}(\%)^{* *}$ & 23,64 & 27,68 & 33,16 & 54,82 & 59,64 & 61,80 \\
\hline \multirow[t]{2}{*}{2017} & SU & EP & PPI & SU & EP & PPI \\
\hline & Alta & Alta & Alta & Baixa & Baixa & Baixa \\
\hline Média & 7,16 & 6,50 & 5,94 & 5,91 & 5,75 & 5,39 \\
\hline Mediana & 7,51 & 6,85 & 5,99 & 6,60 & 6,59 & 6,09 \\
\hline $\mathrm{DP}^{*}$ & 1,65 & 1,91 & 1,89 & 2,71 & 2,86 & 2,89 \\
\hline $\mathrm{CV}(\%)^{* *}$ & 23,04 & 29,38 & 31,82 & 45,85 & 49,74 & 53,62 \\
\hline
\end{tabular}

Fonte: Os Autores.

* DP = Desvio Padrão; ** CV = Coeficiente de Variação.

Os resultados referentes ao índice de desempenho, quando analisados por meio da média ponderada nos grupos SU, EP e PPI (Tabela 8), são similares nos quatro anos de análise para os cursos de alta demanda, como também para os cursos de baixa demanda, ou seja, não apresentam diferenças relevantes dentro de cada uma das duas categorias de demanda social, mas apresentam maior variação dos grupos SU, EP e PPI nos cursos de baixa demanda social. 
Tabela 8 - Média Ponderada para os grupos SU, EP e PPI em cursos de alta e baixa demanda social, no período de 2014 a 2017

\begin{tabular}{|c|c|c|c|c|c|c|}
\hline 2014 & SU & EP & PPI & SU & EP & PPI \\
\hline & Alta & Alta & Alta & Baixa & Baixa & Baixa \\
\hline Média & 6,67 & 6,33 & 6,25 & 5,15 & 5,32 & 4,47 \\
\hline Mediana & 7,08 & 6,68 & 6,70 & 5,71 & 6,24 & 4,68 \\
\hline $\mathrm{DP}^{*}$ & 1,87 & 1,90 & 2,05 & 2,93 & 2,97 & 3,07 \\
\hline $\mathrm{CV}(\%)^{* *}$ & 28,04 & 30,02 & 32,80 & 56,89 & 55,83 & 68,68 \\
\hline \multirow[t]{2}{*}{2015} & $\mathrm{SU}$ & EP & PPI & SU & EP & PPI \\
\hline & Alta & Alta & Alta & Baixa & Baixa & Baixa \\
\hline Média & 6,76 & 6,78 & 6,29 & 5,21 & 5,35 & 5,64 \\
\hline Mediana & 7,02 & 6,95 & 6,36 & 5,69 & 6,39 & 6,27 \\
\hline DP* & 1,78 & 1,63 & 1,90 & 2,83 & 2,88 & 2,71 \\
\hline $\mathrm{CV}(\%)^{* *}$ & 26,33 & 24,04 & 30,21 & 54,32 & 53,83 & 48,05 \\
\hline \multirow[t]{2}{*}{2016} & SU & EP & PPI & SU & EP & PPI \\
\hline & Alta & $\underline{\text { Alta }}$ & $\underline{\text { Alta }}$ & Baixa & Baixa & Baixa \\
\hline Média & 6,86 & 6,38 & 5,79 & 5,27 & 4,94 & 4,98 \\
\hline Mediana & 7,15 & 6,68 & 6,05 & 5,85 & 5,20 & 5,87 \\
\hline DP* & 1,66 & 1,83 & 1,98 & 2,91 & 2,98 & 3,10 \\
\hline $\mathrm{CV}(\%)^{* *}$ & 24,20 & 28,68 & 34,20 & 55,22 & 60,32 & 62,25 \\
\hline \multirow[t]{2}{*}{2017} & SU & EP & PPI & SU & EP & PPI \\
\hline & Alta & Alta & $\underline{\text { Alta }}$ & Baixa & Baixa & Baixa \\
\hline Média & 6,99 & 6,28 & 5,71 & 5,87 & 5,71 & 5,35 \\
\hline Mediana & 7,33 & 6,62 & 5,82 & 6,60 & 6,56 & 6,13 \\
\hline DP* & 1,66 & 1,93 & 1,95 & 2,74 & 2,89 & 2,92 \\
\hline $\mathrm{CV}(\%)^{* *}$ & 23,75 & 30,73 & 34,15 & 46,68 & 50,61 & 54,58 \\
\hline
\end{tabular}

Fonte: Os Autores.

* DP = Desvio Padrão; ** CV = Coeficiente de Variação.

A porcentagem em disciplinas aprovadas (índice de desempenho) nos grupos SU, EP e PPI, na categoria alta demanda social, indica um bom aproveitamento. Durante os quatro anos avaliados, apresentam média acima de $77 \%$ e mediana média $88 \%$. Para a categoria baixa demanda social, a menor percentagem média de disciplinas aprovadas nos quatro anos resulta em $66 \%$ para média e $77 \%$ para mediana média (Tabela 9). Observa-se, também, que os resultados no quesito analisado não apresentam diferenças relevantes quando comparados os grupos SU, EP e PPI dentro de cada uma das duas categorias de demanda social. 
Tabela 9 - Índice de Desempenho (porcentagem de disciplinas aprovadas) para os grupos SU, EP e PPI em cursos de alta e baixa demanda social, no período de 2014 a 2017

\begin{tabular}{|c|c|c|c|c|c|c|}
\hline 2014 & SU & EP & PPI & SU & EP & PPI \\
\hline & $\underline{\text { Alta }}$ & $\underline{\text { Alta }}$ & $\underline{\text { Alta }}$ & $\underline{\text { Baixa }}$ & $\underline{\text { Baixa }}$ & $\underline{\text { Baixa }}$ \\
\hline Média & 90,17 & 85,41 & 85,55 & 73,49 & 74,46 & 66,24 \\
\hline Mediana & 100,00 & 96,92 & 98,97 & 91,01 & 88,93 & 77,78 \\
\hline $\mathrm{DP}^{*}$ & 17,91 & 21,58 & 21,31 & 31,33 & 31,31 & 34,91 \\
\hline $\mathrm{CV}(\%)^{* *}$ & 19,86 & 25,27 & 24,91 & 42,63 & 42,05 & 52,70 \\
\hline \multirow[t]{2}{*}{2015} & SU & $\mathrm{EP}$ & PPI & SU & EP & PPI \\
\hline & $\underline{\text { Alta }}$ & $\underline{\text { Alta }}$ & $\underline{\text { Alta }}$ & $\underline{\text { Baixa }}$ & $\underline{\text { Baixa }}$ & $\underline{\text { Baixa }}$ \\
\hline Média & 90,60 & 89,72 & 85,90 & 72,09 & 72,78 & 77,86 \\
\hline Mediana & 100,00 & 100,00 & 95,56 & 87,03 & 90,26 & 93,83 \\
\hline $\mathrm{DP}^{*}$ & 17,61 & 19,21 & 19,38 & 31,72 & 31,92 & 28,81 \\
\hline $\mathrm{CV}(\%)^{* * *}$ & 19,44 & 21,41 & 22,56 & 44,00 & 43,86 & 37,00 \\
\hline \multirow[t]{2}{*}{2016} & SU & EP & PPI & SU & EP & PPI \\
\hline & Alta & Alta & $\underline{\text { Alta }}$ & Baixa & $\underline{\text { Baixa }}$ & $\underline{\text { Baixa }}$ \\
\hline Média & 91,55 & 85,53 & 78,00 & 75,83 & 74,18 & 73,36 \\
\hline Mediana & 100,00 & 96,77 & 88,35 & 91,78 & 90,91 & 91,84 \\
\hline $\mathrm{DP}^{*}$ & 16,22 & 21,22 & 26,64 & 29,42 & 31,12 & 32,58 \\
\hline $\mathrm{CV}(\%)^{* *}$ & 17,72 & 24,81 & 34,15 & 38,80 & 41,95 & 44,41 \\
\hline \multirow[t]{2}{*}{2017} & SU & EP & PPI & SU & EP & PPI \\
\hline & $\underline{\text { Alta }}$ & $\underline{\text { Alta }}$ & $\underline{\text { Alta }}$ & $\underline{\text { Baixa }}$ & $\underline{\text { Baixa }}$ & $\underline{\text { Baixa }}$ \\
\hline Média & 92,18 & 84,77 & 77,70 & 81,62 & 79,24 & 76,68 \\
\hline Mediana & 100,00 & 100,00 & 88,45 & 100,00 & 100,00 & 95,24 \\
\hline $\mathrm{DP}^{*}$ & 17,81 & 23,63 & 26,80 & 28,22 & 29,36 & 31,51 \\
\hline $\mathrm{CV}(\%)^{* *}$ & 19,32 & 27,88 & 34,49 & 34,57 & 37,05 & 41,09 \\
\hline
\end{tabular}

Fonte: Os Autores.

* DP = Desvio Padrão; ** CV = Coeficiente de Variação.

A Tabela 10 apresenta a avaliação da frequência às aulas nos grupos analisados. A média da frequência é semelhante nos três grupos no decorrer dos anos, tanto para a categoria de alta quanto baixa demanda, e esta última possui valores menores, no entanto, todos são valores superiores a $74 \%$ de frequência. ${ }^{7}$

\footnotetext{
${ }^{7} \mathrm{Na}$ UNESP, a frequência mínima para a aprovação é de $70 \%$.
} 
Tabela 10 - Frequência Média para os grupos SU, EP e PPI em cursos de alta e baixa demanda social, no período de 2014 a 2017

\begin{tabular}{|c|c|c|c|c|c|c|}
\hline 2014 & SU & EP & PPI & SU & EP & PPI \\
\hline & $\underline{\text { Alta }}$ & $\underline{\text { Alta }}$ & $\underline{\text { Alta }}$ & Baixa & Baixa & Baixa \\
\hline Média & 89,12 & 88,34 & 88,82 & 78,71 & 79,92 & 74,56 \\
\hline Mediana & 92,66 & 91,63 & 92,10 & 87,52 & 88,66 & 84,59 \\
\hline $\mathrm{DP}^{*}$ & 10,96 & 11,49 & 12,74 & 19,41 & 18,68 & 21,92 \\
\hline $\mathrm{CV}(\%)^{* *}$ & 12,30 & 13,01 & 14,34 & 24,66 & 23,37 & 29,40 \\
\hline \multirow[t]{2}{*}{2015} & $\mathrm{SU}$ & EP & PPI & $\mathrm{SU}$ & EP & PPI \\
\hline & $\underline{\text { Alta }}$ & $\underline{\text { Alta }}$ & $\underline{\text { Alta }}$ & $\underline{\text { Baixa }}$ & $\underline{\text { Baixa }}$ & $\underline{\text { Baixa }}$ \\
\hline Média & 90,19 & 91,31 & 90,37 & 78,31 & 80,67 & 82,30 \\
\hline Mediana & 92,99 & 93,20 & 92,79 & 86,86 & 89,37 & 89,82 \\
\hline $\mathrm{DP}^{*}$ & 10,09 & 7,50 & 10,53 & 20,03 & 19,99 & 17,94 \\
\hline $\mathrm{CV}(\%)^{* *}$ & 11,19 & 8,21 & 11,65 & 25,58 & 24,78 & 21,80 \\
\hline \multirow[t]{2}{*}{2016} & SU & EP & PPI & SU & EP & PPI \\
\hline & $\underline{\text { Alta }}$ & $\underline{\text { Alta }}$ & $\underline{\text { Alta }}$ & Baixa & Baixa & $\underline{\text { Baixa }}$ \\
\hline Média & 91,62 & 91,13 & 89,41 & 79,30 & 78,60 & 77,72 \\
\hline Mediana & 100,00 & 93,91 & 92,92 & 88,53 & 87,59 & 87,42 \\
\hline DP* & 16,23 & 9,42 & 9,48 & 20,40 & 20,97 & 21,42 \\
\hline $\mathrm{CV}(\%)^{* *}$ & 17,71 & 10,34 & 10,60 & 25,73 & 26,68 & 27,56 \\
\hline \multirow[t]{2}{*}{2017} & SU & EP & PPI & SU & EP & PPI \\
\hline & Alta & $\underline{\text { Alta }}$ & $\underline{\text { Alta }}$ & Baixa & Baixa & $\underline{\text { Baixa }}$ \\
\hline Média & 92,60 & 91,17 & 91,57 & 83,59 & 83,75 & 82,15 \\
\hline Mediana & 94,97 & 94,04 & 92,76 & 90,69 & 91,10 & 90,07 \\
\hline $\mathrm{DP}^{*}$ & 8,61 & 10,53 & 6,55 & 18,38 & 18,68 & 19,51 \\
\hline $\mathrm{CV}(\%)^{* *}$ & 9,30 & 11,55 & 7,15 & 21,99 & 22,30 & 23,75 \\
\hline
\end{tabular}

Fonte: Os Autores.

* DP = Desvio Padrão; ** CV = Coeficiente de Variação.

É importante reiterar que o Programa de Inclusão implantado na UNESP foi gradativo e, consequentemente, em 2014 e 2015, o ingresso de estudantes foi, respectivamente, de $15 \%$ e $25 \%$ de egressos da escola pública e destes percentuais reservados $35 \%$ para pretos, pardos e indígenas (PPIs). Por estes serem ainda percentuais pequenos de ingresso, os resultados devem ser tratados com cautela. Cabe salientar que, a partir de 2018, foi atingida a meta de inclusão de $50 \%$ de egressos da escola pública, dos quais 35\% são de PPIs. Este índice permitirá, nos próximos anos, uma análise comparativa mais fidedigna do rendimento acadêmico dos alunos da UNESP e dos efeitos do programa de inclusão para os estudantes cotistas e não cotistas. Porém, mesmo os resultados sendo preliminares, a análise comparativa dos dados de 30.838 estudantes ingressantes, no período de 2014 a 2017, nos grupos por ano e forma de ingresso, mostrou que, de um modo geral, não há diferenças relevantes entre os grupos pesquisados no 
que se refere aos valores da mediana do Coeficiente de Rendimento Médio. Tal resultado pode ser mais bem observado no Gráfico 3.

\section{Gráfico 3 - Coeficiente de Rendimento Médio (valores da mediana) nos grupos SU, EP e PPI por ano e forma de ingresso}

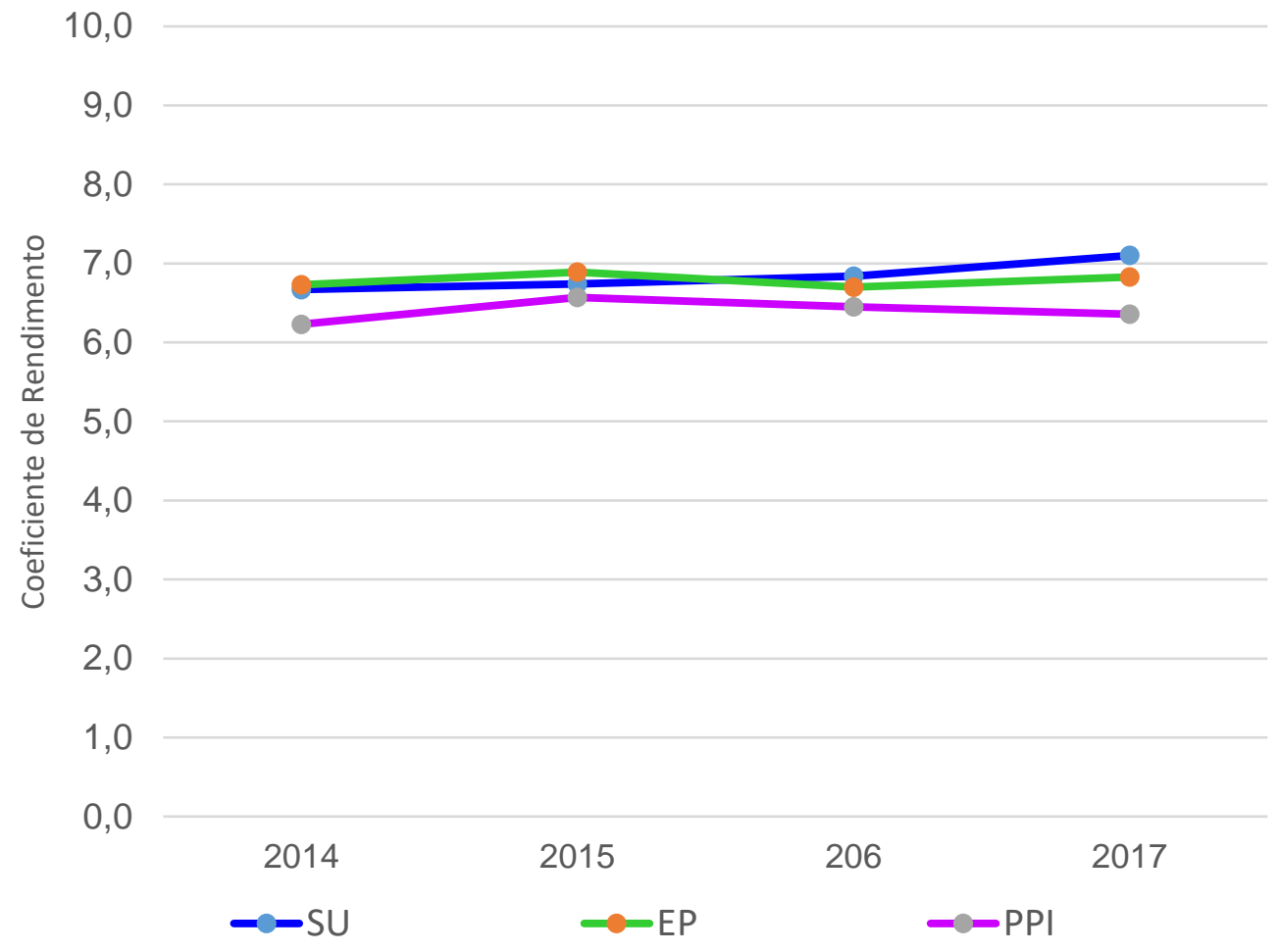

Fonte: Os Autores.

A análise, em separado, no conjunto de cursos de alta demanda social e no conjunto de cursos de baixa demanda, aponta algumas diferenças nas comparações entre SU, EP e PPIs. No conjunto de cursos de alta demanda social, os valores de Coeficiente de Rendimento Médio (valores da mediana) são bastante próximos entre SU e EP e um pouco mais distantes nos PPI, mas com coeficientes maiores que 6,0 (Gráfico 4). No conjunto de cursos de baixa demanda social, os valores de Coeficiente de Rendimento Médio (valores da mediana) sãos próximos, mas apresentam maior disparidade no primeiro ano analisado, em 2014, atingindo o coeficiente menor que 5,0. Neste ano, ingressaram na UNESP pelo projeto de inclusão apenas $15 \%$ de egressos de escolas públicas. No entanto, nos anos subsequentes, nos quais ingressaram um pouco mais de egressos de escolas públicas, observou-se que a média de rendimento acadêmico se altera de modo relevante de um ano para outro, atingindo coeficientes 6,0 e 6,5 (Gráfico 4), mais próximos aos coeficientes dos cursos de alta demanda social. 
Gráfico 4 - Coeficiente de Rendimento Médio (valores da mediana) nos grupos SU, EP e PPI, em cursos de alta demanda social e de baixa demanda social, por ano e forma de ingresso

Alta Demanda Social

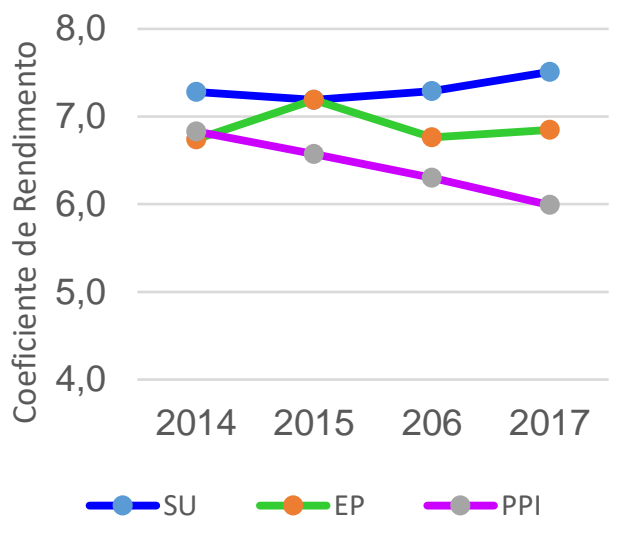

Baixa Demanda Social

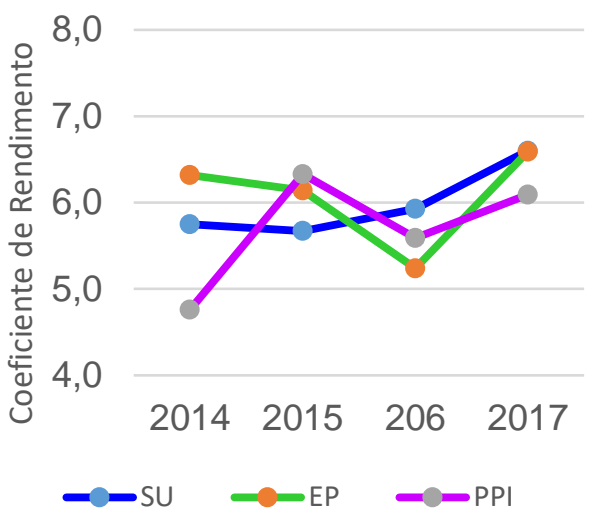

Fonte: Os Autores.

Vários aspectos podem e devem ser destacados na continuidade desta pesquisa em andamento na UNESP. As possibilidades de análise dos dados obtidos na população dos estudantes cotistas e não cotistas são amplas. Sem dúvida, é preciso incluir a análise específica de cada curso e turno da instituição, a análise por áreas de conhecimento, por perfil socioeconômico dos alunos, os impactos dos auxílios de permanência, etc. Sabe-se, também, que a maioria dos cursos noturnos e de licenciatura das universidades públicas são cursos de baixa demanda, com infraestrutura funcional abaixo dos cursos integrais e diurnos e que possuem estudantes que trabalham durante todo dia. Nestes cursos, tais variáveis contribuem para que o rendimento acadêmico seja menor, sendo o aluno cotista ou não. Conforme retratam Terribili Filho e Nery (2009), esse rendimento menor não é uma novidade inclusiva. Com certeza o aprofundamento de estudos sobre estas variáveis poderá fornecer subsídios para a avaliação, aprimoramento e efetivação da política de inclusão na UNESP.

\section{Considerações finais}

De um modo geral, os dados coletados neste estudo indicaram que não há diferenças relevantes de rendimento acadêmico entre os estudantes que ingressaram na UNESP pelo sistema universal e aqueles que ingressaram pelo sistema de reserva de vagas, no período de 2014 a 2017. Tais resultados, embora preliminares, contribuem para desmistificar a ideia preconcebida de que os estudantes que ingressam pelo Sistema de Reserva de Vagas necessariamente obtêm resultados inferiores àqueles que ingressaram pelo Sistema Universal. 
No entanto, conforme foi constatado, em alguns casos há uma maior variação no desempenho acadêmico de estudantes nos grupos EP e PPI. Tais dados podem indicar que é necessário o oferecimento de mais suportes aos alunos para a vivência universitária e permanência estudantil; não apenas suporte financeiro, mas também pedagógico, especialmente para egressos da escola pública em cursos de baixa demanda social, cujas médias de rendimento acadêmico se apresentam em alguns casos abaixo de 5,0 (nota mínima para aprovação nas disciplinas).

Ações dessa natureza são fundamentais para uma melhor equalização e compreensão dos fatores que influenciam ou não na adaptação acadêmica de um pequeno contingente de alunos. Além disso, não parece adequado enfatizar o rendimento acadêmico dos alunos cotistas como indicador isolado de adaptação ou não adaptação acadêmica. O foco apenas no desempenho dos alunos pode reificar a ideia de que um eventual fracasso no rendimento é de responsabilidade individual, seja por falta de competência seja por distorções de formação. Desse modo, é importante também tomar em consideração as ações, esforços e responsabilidades institucionais frente às implicações do programa de ação afirmativa instituído. É preciso indagar: Quais ações transversais são desenvolvidas voltadas para a permanência dos estudantes na universidade? Quais mudanças institucionais o programa trouxe em termos de interesse institucional e acadêmico pelo tema da diversidade e das relações étnicoraciais?

São questões deste tipo que têm levado a UNESP, desde 2014, a instituir novas ações e modalidades de assistência ao estudante visando, em especial, aos alunos que ingressaram pelo SRVEBP. Tais ações, embora ainda moderadas, têm por finalidade promover a permanência dos estudantes e evitar a retenção e a evasão. Afinal, incluir estudantes no ensino superior não significa apenas abrir vagas para que determinado contingente de alunos ingresse na universidade. É preciso criar condições para que o estudante possa concluir o curso e construir um campo de emancipação e significação orientado pelo conhecimento científico e para o exercício da cidadania.

\section{Agradecimentos}

À Pró Reitoria de Graduação (PROGRAD), especialmente à Equipe do Sistema de Graduação da UNESP (SISGRAD) e à Fundação para o Vestibular da UNESP (VUNESP) pelo apoio e colaboração no desenvolvimento deste estudo.

À Coordenadoria de Permanência Estudantil da UNESP (COPE). 


\section{Referências}

BIEMBENGUT, T. M.; PACHECO, P. S.; CONINCK, J. C. P. Análise do desempenho acadêmico de cotistas e não cotistas na UTFPR - Curitiba. Cadernos de Pesquisa, São Luís, v. 25, n. 1, p. 35-48, jan./mar. 2018. Disponível em: http://www.periodicoseletronicos. ufma.br/index.php/cadernosdepesquisa/article/view/8854. Acesso em: 9 jul. 2018.

BRASIL. Decreto n 7.234 , de 19 de julho de 2010. Dispõe sobre o Programa Nacional de Assistência Estudantil - PNAES. Brasília, DF: Presidência da República, 2010. Disponível em: http://www.planalto.gov.br/ccivil_03/_ato2007-2010/2010/decreto/d7234.htm. Acesso em: 24 nov. 2018.

BRASIL. Presidência da República. Casa Civil. Subchefia para Assuntos Jurídicos. Lei no 12.711, de 29 de agosto de 2012. Dispõe sobre o ingresso nas universidades federais e nas instituições federais de ensino técnico de nível médio e dá outras providências. Brasília, DF: Presidência da República, 2012. Disponível em: http://bit.ly/2f5Dq8r. Acesso em: 23 abr. 2016.

CARDOSO, C. B. Efeitos da política de cotas na Universidade de Brasília: uma análise do rendimento e da evasão. 2008. 134f. Dissertação (Mestrado em Educação) - Universidade de Brasília, Brasília, 2008.

CARVAlHO, J. J. A política de cotas no Ensino Superior: Ensaio descritivo e analítico do Mapa das Ações Afirmativas no Brasil. Brasília: Ministério da Educação/Instituto de Inclusão no Ensino Superior e na Pesquisa, 2016.

CERVI, E. U. Ações afirmativas no vestibular da UFPR entre 2005 e 2012: de política afirmativa racial a política afirmativa de gênero. Revista Brasileira de Ciência Política, Brasília, n. 11, p. 63-88, maio/ago. 2013. Disponível em: https://doi.org/10.1590/S010333522013000200003. Acesso em: 24 nov. 2018.

CORREIO, L. C. A. Assistência Estudantil na Política de Educação Superior no Brasil.

Revista Brasileira de Educação Superior, Passo Fundo, v. 4, n. 2, p. 1-15. 2018. Disponível em: https://seer.imed.edu.br/index.php/REBES/rt/printerFriendly/2413/2300. Acesso em: 16 ago. 2019.

CROSBY, F. J.; IYER, A.; SINCHAROEN, S. Understanding affirmative action. Annual Review of Psychology, Palo Alto, CA/USA, v. 57, p. 585-611, 2006. Disponível em: https://doi.org/10.1146/annurev.psych.57.102904.190029. Acesso em: 24 nov. 2018.

GARCIA, F. A. C.; JESUS, G. R. Uma avaliação do sistema de cotas raciais da Universidade de Brasília. Estudos em Avaliação Educacional, São Paulo, v. 26, n. 61, p.146-165, jan./abr. 2015. Disponível em: http://dx.doi.org/10.18222/eae266102773. Acesso em: 26 abr. 2016.

GUERRINI, D. et al. Acesso e democratização do ensino superior com a Lei ${ }^{\circ} 12.711 / 2012$ : o câmpus de Londrina da Universidade Tecnológica Federal do Paraná (UTFPR). Revista Brasileira de Estudos Pedagógicos, Brasília, v. 99, n. 251, p. 17-36, jan./abr. 2018. Disponível em: http://dx.doi.org/10.24109/21766681.rbep.99i251.3243. Acesso em: 09 jul. 2018.

LIMA, M. E. O.; NEVES, P. S. C.; SILVA, P. B. A implantação de cotas na universidade: paternalismo e ameaça à posição dos grupos dominantes. Revista Brasileira de Educação, 
Rio de Janeiro, v. 19, n. 56, p. 141-163, 2014. Disponível em: http://www.scielo.br/scielo.php ?script=sci_arttext\&pid=S141324782014000100008\&lng=en\&nrm=iso. Acesso em: 23 abr. 2016.

MENDES JUNIOR, A. A. F. Uma análise da progressão dos alunos cotistas sob a primeira ação afirmativa brasileira no ensino superior: o caso da Universidade do Estado do Rio de Janeiro (UERJ). Ensaio: Avaliação e Políticas Públicas em Educação, Rio de Janeiro, v. 22, n. 82, p. 31-56, jan./mar. 2014. Disponível em: http://www.scielo.br/pdf/ensaio/v22n82/a03v 22n82.pdf. Acesso em: 24 nov. 2018.

MENIN, M. S. S. et al. Representações de estudantes universitários sobre alunos cotistas: confronto de valores. Educação e Pesquisa, São Paulo, v. 34, n. 2, p. 255-272, maio/ago. 2008. Disponível em: http://www.scielo.br/pdf/ep/v34n2/04.pdf. Acesso em: 23 abr. 2016.

NUNES, R. S. R.; VELOSO, T. C. M. A. A permanência na educação superior: múltiplos olhares. Educação e Fronteiras On Line, Dourados, M/S, v. 6, n.16., p. 48 - 63, jan./abril. 2016. Disponível em: http://ojs.ufgd.edu.br/index.php/educacao/article/view/5708 . Acesso em: 08 jul. 2019.

SOUZA, M. A. Desempenho dos candidatos no vestibular e o sistema de cotas na UERJ. Ensaio: Avaliação e Políticas Públicas em Educação, Rio de Janeiro, v. 20, n. 77, p. 701724, out./dez. 2012. Disponível em: http://www.scielo.br/pdf/ensaio/v20n77/a05v20n77.pdf. Acesso em: 25 nov. 2014.

TERRIBILI FILHO, A.; NERY, A. C. B. Ensino superior noturno no Brasil: história, atores e políticas. RBPAE, Brasília, v. 25, n. 1, p. 61-81, 2009.

VASCONCELOS, M. S.; GALHARDO, E. O programa de inclusão na UNESP: valores, contradições e ações afirmativas. Revista Ibero-Americana de Estudos em Educação, Araraquara, v. 11, n. 25, p. 285-306, 2016. Disponível em: https://periodicos.fclar.unesp.br/ iberoamericana/article/view/8553. Acesso em: 24 nov. 2018.

VELLOSO, J. Cotistas e não-cotistas: rendimento de alunos da Universidade de Brasília. Cadernos de Pesquisa, São Paulo, v. 39, n. 137, p. 621-644, 2009. Disponível em: http://dx.doi.org/10.1590/S0100-15742009000200014. Acesso em: 23 abr. 2016.

VIBETTO, A. (org.). Políticas, poéticas e práticas pedagógicas. Rio de Janeiro: Lamparina, 2014.

VIDIGAL, C. B. R. Racial and low-income quotas in Brazilian universities: impact on academic performance", Journal of Economic Studies, v. 45 n. 1, p. 156-176, 2018. Disponível em: https://doi.org/10.1108/JES-10-2016-0200. Acesso em: 26 jul. 2018.

ZAGO, N. Do acesso à permanência no ensino superior: percursos de estudantes universitários de camadas populares. Revista Brasileira de Educação, Rio de Janeiro, v. 11, n. 32, p. 226-237, ago. 2006. Disponível em: http://www.scielo.br/scielo.php?script= sciarttext\&pid=S141324782006000200003\&lng=en\&nrm=iso. Acesso em: 26 abr. 2016.

WAINER, J.; MELGUIZO, T. Políticas de inclusão no ensino superior: avaliação do desempenho dos alunos baseado no Enade de 2012 a 2014. Educação e Pesquisa, São Paulo, 
v. 44, e162807, p. 01-15, 2018. Disponível em:

https://www.scielo.br/pdf/ep/2017nahead/1517-9702-ep-S1517-9702201612162807.pdf.

Acesso em: 09 set. 2018.

WINTHER, J. M.; GOLGHER, A. B. Uma investigação sobre a aplicação de bônus adicional como política de ação afirmativa na Universidade Federal de Minas Gerais (UFMG). Revista Brasileira de Estudos de População, Rio de Janeiro, v. 27, n. 2, p. 333-359, 2010. Disponível em: http://www.scielo.br/scielo.php?script=sci_arttext\&pid=S01023098 2010000200007\&lng=e\&nrm=iso. Acesso em: 26 abr. 2016. 